\title{
Estrategias de permanencia e instrumentos de reproducción universitarios en Córdoba, Argentina, 2017
}

\author{
Ana-María Antolin-Solache y Manuel-Alejandro Giovine
}

\section{RESUMEN}

El aumento sostenido en la matrícula universitaria de Córdoba, Argentina, incluye una creciente proporción de estudiantes que transitan por la difícil situación de dilación en sus estudios, frente a la cual establecen estrategias de permanencia en el nivel, que hemos sistematizado como estrategias de persistencia y estrategias de sustitución. Asumiendo una perspectiva bourdieusiana, reconstruimos el espacio de las titulaciones universitarias de Córdoba a partir de la clasificación de los títulos de pregrado y grado (CINE 5 y 6), por medio de una técnica multidimensional de análisis de datos y una metodología de clasificación jerárquica ascendente. La tipología de titulaciones obtenida permite reconstruir el estado de la oferta universitaria que, en tanto instrumento de reproducción disponible, constituye el espacio de posibilidades y limitaciones para las estrategias de permanencia, especialmente las de sustitución, dentro del nivel universitario.

Palabras clave: cambio de carrera, elección de carrera, estrategias educativas, política universitaria, Argentina.

Ana-María Antolin-Solache ana_antolin@unc.edu.ar Argentina. Licenciada en Ciencias de la Educación, Universidad Nacional de Córdoba (UNC), Argentina. Profesora titular, Facultad de Salud y Educación, Universidad Provincial de Córdoba, Argentina; Profesora asistente, Facultad de Ciencias Sociales, UNC, Argentina; integrante del Área Estadística del Ministerio de Educación de la provincia de Córdoba. Temas de investigación: sociología de la educación, trayectorias educativas, formación profesional. ORCID: https://orcid.org/0000-0001-6839-5385.

\section{Manuel Alejandro Giovine}

manuel.giovine@unc.edu.ar

Argentino/Italiano. Doctor en Estudios Sociales de América Latina con mención en Sociología, Centro de Estudios Avanzados, Universidad Nacional de Córdoba (UNC), Argentina; especialista en producción y análisis de información para políticas públicas, Centro de Estudios Avanzados, UNC, Argentina. Profesor asistente, Facultad de Filosofía y Humanidades, UNC, Argentina; becario posdoctoral Instituto de Humanidades, UNC-CONICET, Argentina. Temas de investigación: sociología de la educación, educación de las élites, internacionalización de la educación, educación comparada. ORCID: https://orcid.org/0000-0002-9330-3136. 
Estratégias de permanência e instrumentos de reprodução universitários em Córdoba, Argentina, 2017

\title{
RESUMO
}

O aumento contínuo da matrícula universitária de Córdoba, Argentina, inclui uma crescente proporção de estudantes que transitam pela difícil situação de dilação em sus estudos, frente à qual estabelecem estratégias de permanência no nível, que temos sistematizado como estratégias de persistência e estratégias de substituição. Assumindo uma perspectiva bourdieusiana, reconstruímos o espaço das certificações universitárias de Córdoba a partir da classificação dos diplomas de graduação (CINE 5 y 6), por meio de uma técnica multidimensional de análise de dados e uma metodologia de classificação hierárquica ascendente. A tipologia de certificações obtida permite reconstruir o estado da oferta universitária que, em tanto instrumento de reprodução disponível, constitui o espaço de possibilidades e limitações para as estratégias de permanência, especialmente as de substituição, dentro do nível universitário.

Palavras chave: mudança de carreira, escolha de carreira, estratégias educativas, política universitária, Argentina.

Permanence strategies and instruments of university reproduction in Córdoba, Argentina, 2017

\begin{abstract}
The sustained increase in university enrollment in Córdoba, Argentina, includes a growing proportion of students who go through the difficult situation of procrastination in their studies. To deal with this situation, the students establish strategies of permanence in higher education, which we have systematized as persistence strategies and substitution strategies. Assuming a Bourdieusian perspective, we reconstruct the space of university degrees in Córdoba from the classification of undergraduate and graduate degrees (ISCED 5 and 6), by means of a multidimensional technique of data analysis and an ascending hierarchical classification methodology. The typology of degrees obtained allows us to reconstruct the state of university supply which, as an instrument of available reproduction, constitutes the space of possibilities and limitations for permanence strategies, especially those of substitution, in higher education.
\end{abstract}

Key words: career change, career choice, educational strategies, university policy, Argentina. 


\section{Surgimiento y expansión de la educación universitaria en Córdoba}

Se conoce por Córdoba, en la República Argentina, a una provincia mediterránea y a su ciudad capital. Fundada en 1573, es sede de la primera universidad argentina y una de las primeras de Sudamérica. Desde entonces comenzó a gestarse un aura doctoral asociada a la ciudad que le vale, incluso en la actualidad, el mote de "la docta". La Reforma Universitaria de 1918 llevó a ambas, ciudad y universidad, a un reconocimiento entre sus pares.

A 100 años de la Reforma y a 70 años de la gratuidad de los estudios universitarios (1949) sus principios continúan vigentes. Esos momentos históricos, precursores en la democratización de la educación argentina, permitieron la apertura de los claustros a una incipiente clase media. Y con ello el crecimiento sostenido del acceso al nivel.

Este incremento se agudiza a partir de la recuperación de la democracia en 1983 (Alonso, 2015), cuando el crecimiento en las cifras universitarias muestra los efectos de la democratización del nivel.

La expansión ha implicado que muchas familias enviaran por primera vez a sus hijos a la universidad, dando lugar a los llamados estudiantes de primera generación (García de Fanelli, 2017), que pertenecen en mayor grado a la clase media pero, producto de la reciente obligatoriedad de la educación secundaria en 2006 (Antolín Solache y Giovine, 2019), provienen de todo el abanico social. La democratización entra en conflicto con una universidad que ha formado la élite del país durante siglos, dejando atrás un nivel elitista para avanzar hacia un sistema que tiende, en nuestros días, a la universalización (Suasnábar y Rovelli, 2016). Sin embargo, como lo muestran Accinelli et al. (2016), no podemos hablar todavía de una inclusión real en el nivel, mientras la ampliación en el acceso no se extienda a la permanencia y el egreso.
En Argentina, las instituciones universitarias, junto a la oferta de nivel superior no universitario (anteriormente denominados institutos terciarios), conforman el Nivel de Educación Superior y están regulados por la Ley de Educación Superior 24.521 y su modificatoria 27.204/2015. Las universidades son de gestión estatal, nacional y en menor medida provincial, y privada. Por su parte, la oferta de nivel superior no universitaria opera en su mayoría bajo jurisdicción provincial, ya sea gestión estatal o privada.

Ambos subniveles se diferencian también por la oferta: ${ }^{1}$ los institutos de educación superior no universitarios otorgan titulaciones docentes o técnico-profesionales a nivel de pregrado, mientras que las universidades además otorgan títulos de grado y posgrado. La pertenencia institucional conlleva una diferenciación entre titulaciones que se manifiesta en el alcance laboral y en el plano simbólico.

Según datos oficiales (Dirección General de Planeamiento, Información y Evaluación Educativa, 2017) la oferta de nivel superior no universitario en Córdoba en 2017 está conformada por 213 unidades educativas, que reciben un total de 44681 estudiantes $(16.7 \%)$. En tanto la oferta universitaria está constituida por ocho universidades, que reúnen un total de 223426 estudiantes (83.3\%).

Para esta investigación nos ocuparemos de las estrategias de permanencia dentro de las instituciones universitarias. Esta delimitación, que puede ser considerada como una limitación, no desconoce la existencia de estrategias que articulan con las instituciones terciarias, que dará lugar a otras investigaciones.

La oferta con sede en Córdoba está compuesta por ocho universidades: cuatro dependientes del Estado nacional, una provincial y cuatro privadas. Fueron creadas desde el Virreinato del Perú, hasta 2012.

Córdoba cuenta con la primera universidad estatal y la primera universidad privada autorizada a otorgar títulos habilitantes en el país (Gutiérrez y

\footnotetext{
${ }^{1}$ Para esta investigación tomamos como unidades de análisis los títulos que emite cada universidad, que denominamos titulaciones.
} 
Giovine, 2017; Giovine, 2015). Además, se identificaron otras universidades que no tienen sede principal en esta ciudad pero que están dictando carreras, con modalidad presencial o semipresencial, como la Universidad Nacional de Villa María, la Universidad de Morón o de manera virtual, la Universidad Católica de Santiago del Estero.

La oferta de universidades estatales comprende la Universidad Nacional de Córdoba (UNC), fundada en 1613 y sede de la Reforma Universitaria de 1918; el Instituto Universitario Aeronáutico (IUA), perteneciente a la Universidad de la Defensa Nacional, creado en tanto tal en 2014, pero que inició sus actividades en 1971; la Universidad Tecnológica Nacional-Facultad Regional Córdoba (UTN), que lleva ese nombre desde 1959, habiendo comenzado a funcionar en 1953 como Universidad Obrera, para trabajadores, y la Universidad Provincial de Córdoba (UPC), creada en 2007 sobre la base de ocho institutos de nivel superior preexistentes. Las universidades estatales son gratuitas, por ley $\mathrm{N}^{\circ} 27.204$ (art. 2 bis), y el ingreso libre e irrestricto (art. 7), con excepción de la Universidad de la Defensa.

Entre las universidades privadas, señalamos a la Universidad Católica de Córdoba (UCG), la única confesional. Fundada en 1956, puede otorgar títulos desde 1959. La Universidad Blas Pascal (UBP) se crea en 1990 y la Universidad Empresarial Siglo 21 (UES21) en 1995, ambas a partir de institutos de nivel superior preexistentes. En 2012 abre el Instituto Universitario de Ciencias Biomédicas de Córdoba (IUCBC), que cuenta al momento con autonomía provisoria reconocida. Este último surge en vinculación con el Hospital Privado, en un proceso inverso al de las universidades Nacional y Católica de Córdoba, que crearon sus hospitales-escuela para las respectivas carreras de Medicina. Todas las universidades privadas son aranceladas (ver tabla 1).

Tabla 1. Universidades según fecha de fundación y sector de gestión

\begin{tabular}{|c|c|c|c|c|}
\hline \multirow{2}{*}{ Gestión } & Tradicionales & Modernizadoras & Presidencias Menem & Recientes \\
\hline & Previas a 1970 & Décadas 1970/80 & Década de 1990 & A partir de 2000 \\
\hline \multirow{2}{*}{ Estatales } & $\begin{array}{l}\text { Universidad Nacional de } \\
\text { Córdoba (1613) }\end{array}$ & $\begin{array}{c}\text { Instituto Universitario } \\
\text { Aeronáutico - Universidad de la } \\
\text { Defensa (1971) }\end{array}$ & $\ldots$ & $\begin{array}{l}\text { Universidad Provincial de } \\
\text { Córdoba (2007) }\end{array}$ \\
\hline & $\begin{array}{c}\text { Universidad Tecnológica } \\
\text { Nacional-Facultad Regional } \\
\text { Córdoba (1953) }\end{array}$ & -.. & -.. & -.. \\
\hline \multirow{2}{*}{ Privadas } & $\begin{array}{l}\text { Universidad Católica de } \\
\text { Córdoba (1956) }\end{array}$ & -.. & Universidad Blas Pascal (1990) & $\begin{array}{c}\text { Instituto Universitario de } \\
\text { Ciencias Biomédicas de Córdoba } \\
(2012)\end{array}$ \\
\hline & -.. & $\ldots$ & $\begin{array}{l}\text { Universidad Empresarial Siglo } \\
\qquad 21 \text { (1995) }\end{array}$ & -.. \\
\hline
\end{tabular}

Fuente: elaboración propia a partir de la clasificación propuesta por Fernández Lamarra (2018) e información contenida en las páginas web de las universidades. 
Según datos provistos por la Secretaría de Políticas Universitarias (SPU), en 2017 las ocho universidades e institutos universitarios con sede en Córdoba tienen un total de 223426 estudiantes, el $62.2 \%$ de ellos inscritos en instituciones estatales y el $37.8 \%$ restante en instituciones privadas.

La UNG cuenta con más de 120000 estudiantes, cifra que supera la suma de la matrícula de las universidades restantes. Le sigue la UES21, con prácticamente la mitad de los estudiantes de aquélla. Luego identificamos un grupo de mediano tamaño, entre 8 y 13 mil estudiantes, que incluye a la UTN, la UCG y la UBP. Finalmente, un grupo de menor matrícula con menos de 4 mil estudiantes, donde se encuentran los dos institutos universitarios, el IUAUD y el IUCBC, más la última universidad estatal creada en Córdoba, la UPG (ver gráfico 1).

En 2017 se dictaron 338 titulaciones, el 74\% en universidades estatales y el $36 \%$ restante en privadas. Las titulaciones de grado predominan en la oferta universitaria sobre las de pregrado, representando un $76 \%$ del total.

\section{Gráfico 1. Estudiantes universitarios por universidad y sector de gestión, Córdoba, 2017}

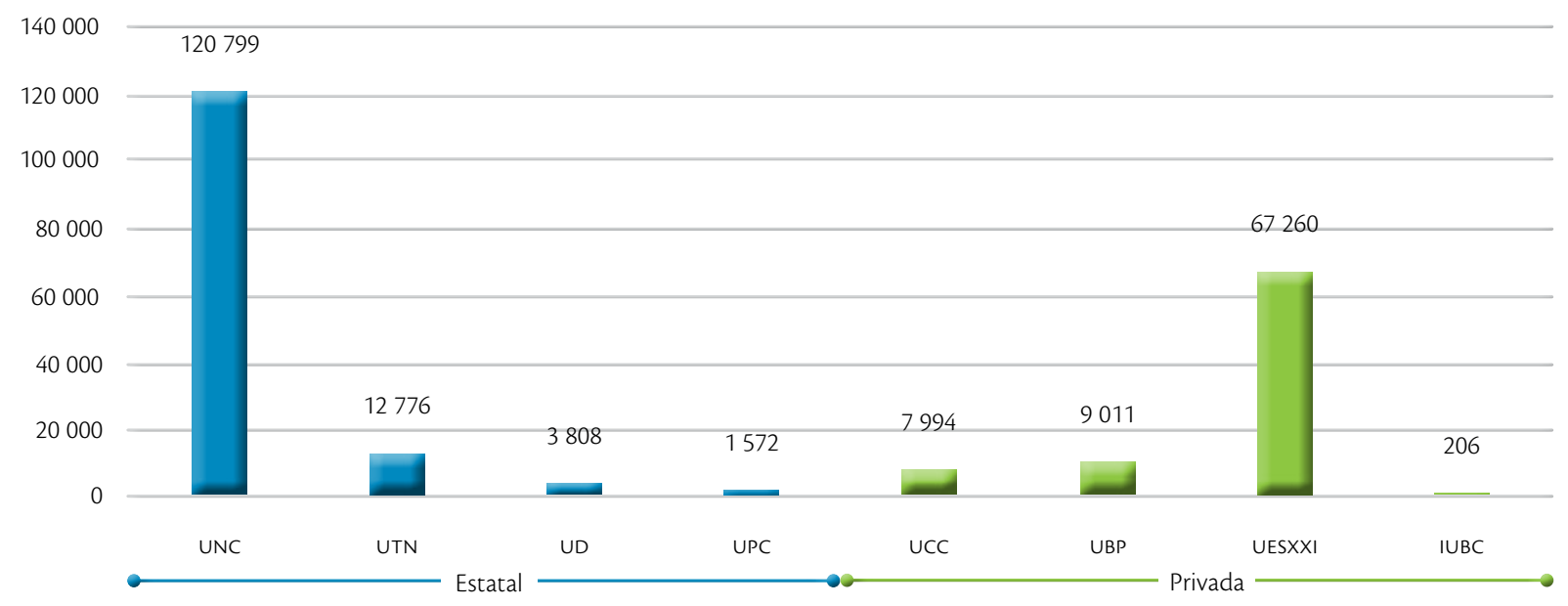

Fuente: elaboración propia en base a datos de la SPU.

\section{Acceder no es todo: dilación en los estudios y estrategias de sustitución}

En un país que sostiene que la educación superior constituye un bien público social y un derecho humano universal y donde las universidades estatales son gratuitas (Ley No 27.204, de implementación efectiva de la responsabilidad del Estado en el nivel de educación superior), esta exploración nos permite problematizar cuestiones relativas a la masividad y a la distancia social y geográfica de los estudiantes en relación con los estudios universitarios. La evolución de las cifras universitarias se puede significar como una democratización del nivel. Sin embargo, la lectura detallada de los datos de Nuevos Inscritos, Reinscritos Netos ${ }^{2}$ y Egresados (ver gráfico 2), nos muestra un aumento desproporcionado de los segundos, que da cuenta de una población que, pudiendo acceder, encuentra dificultades para titularse en los plazos previstos.

\footnotetext{
${ }^{2}$ Denominamos Reinscritos Netos a la variable Reinscritos menos los Egresados de un año académico.
} 
El gráfico muestra un aumento sostenido en la matrícula argentina tanto en las universidades estatales como privadas. No obstante, en Córdoba eso significó cambios morfológicos que llevaron la matrícula de las universidades privadas de un $9 \%$ del total en 2001 a absorber el 38\% en 2016 (SPU).
En este contexto, el acceso a este nivel para las familias cordobesas de menor ingreso familiar per cápita (IPCF) es todavía muy restringido, como se puede ver en el gráfico 3. Fundamentalmente porque no logran finalizar la educación obligatoria (Giovine y Antolín Solache, 2018).

Gráfico 2. Nuevos inscritos, reinscritos netos y egresados, pregrado y grado, Argentina, 1980/1995-2017

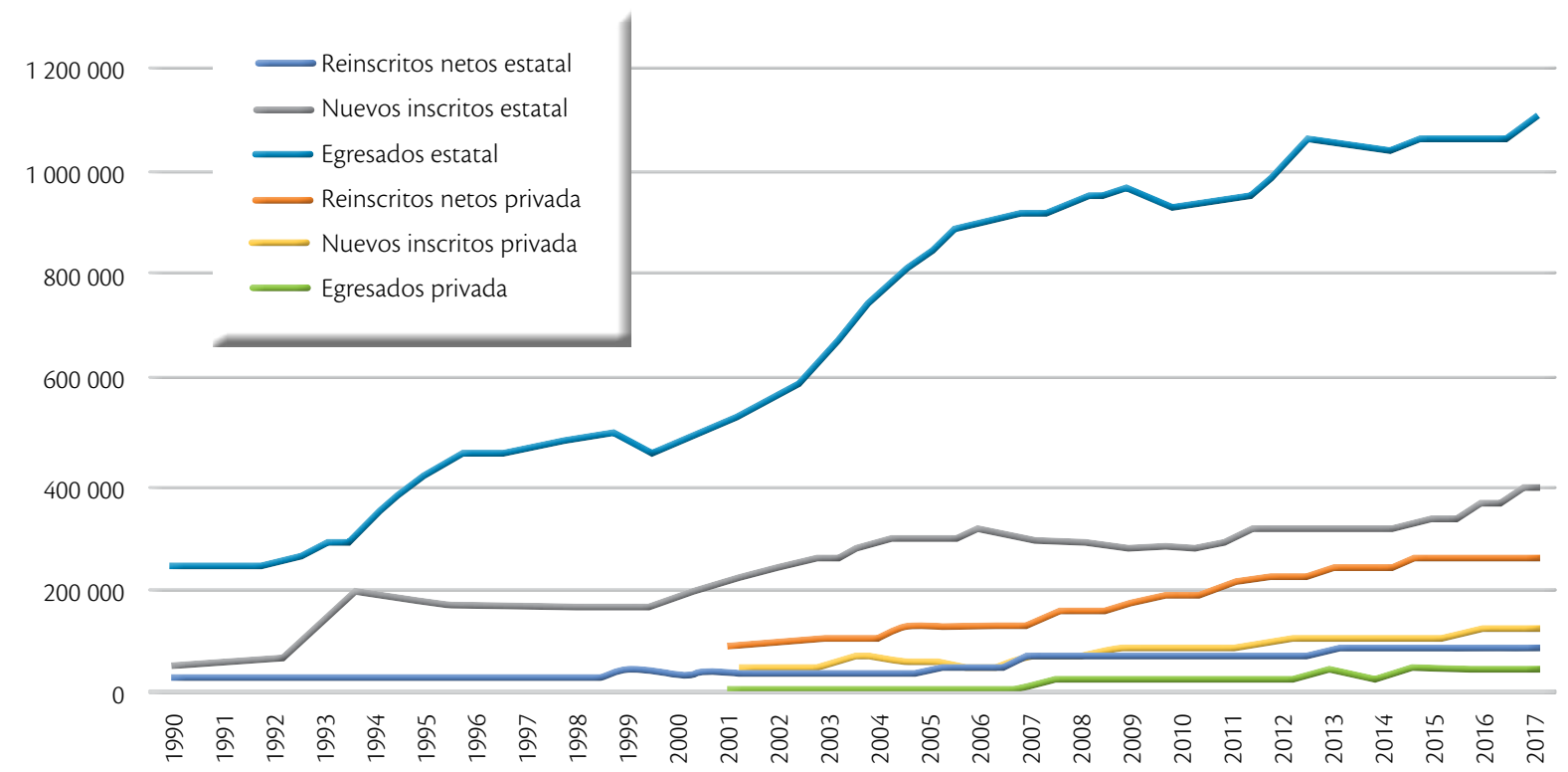

Fuente: elaboración propia en base a datos de la SPU.

\section{Gráfico 3. Acceso y egreso de 25 años y más por quintil de ingresos, años seleccionados, Gran Córdoba ${ }^{3}$}

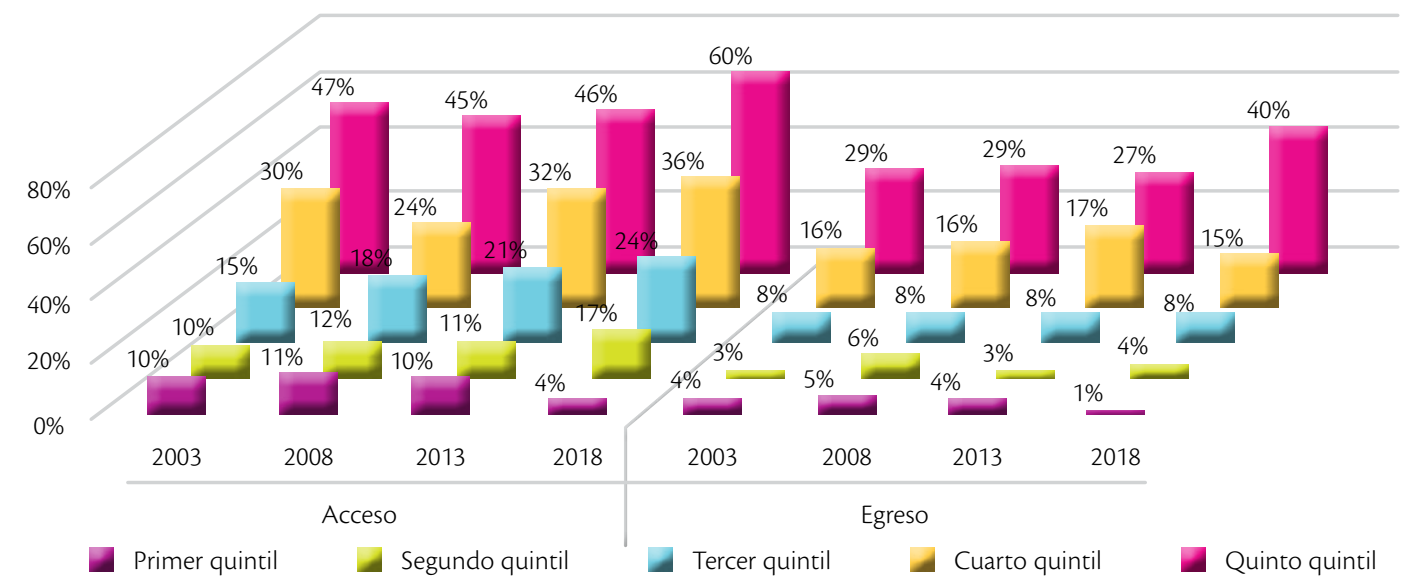

Fuente: elaboración propia en base a datos de la EPH-INDEC

\footnotetext{
${ }^{3}$ El aglomerado Gran Córdoba abarca a la ciudad de Córdoba y un conjunto de localidades cercanas. En 2010 contaba con 1454536 habitantes (INDEC, Censo Nacional de Población, Hogares y Vivienda). Se corresponde con el área muestral de la Encuesta Permanente de Hogares, base del cálculo del WW.
} 
La gran desigualdad en el acceso y egreso del nivel universitario, se incrementa en el periodo. $\mathrm{El}$ acceso de las familias del primer quintil crece levemente entre 2008 y 2013 para caer de un modo considerable en 2018, llegando a un escaso 4\%. En contraste, el acceso del quinto quintil aumenta del 47 al 60\%. Los demás quintiles (2, 3 y 4), también mejoran el acceso entre 2003 y 2018, siendo la población que, junto al quinto quintil, protagoniza la expansión del nivel en estos 15 años. Sin embargo, el egreso dista de democratizarse para toda la población. De hecho, sólo el quinto quintil de IPCF mejora el egreso entre 2003 y 2018, llegando a un $40 \%$. El primer quintil lo empeora claramente, alcanzando apenas un 1\% en 2018 y los quintiles 2, 3 y 4 mantienen la proporción de graduados universitarios.

Por lo tanto, en este periodo aumenta la población de estudiantes de los quintiles 2, 3 y 4 y, al no incrementar su egreso, crece también el volumen de estudiantes que permanecen en el nivel sin finalizarlo.

Desde los estudios iniciales de Vincent Tinto (1989) se entiende que existe una gran variedad de prácticas asociadas a la deserción universitaria; nuestros trabajos nos han permitido reconocer múltiples prácticas asociadas a la permanencia en los estudios universitarios (Giovine y Antolín Solache, 2019). En aquella mirada el fenómeno está asociado predominantemente a comportamientos individuales (Tinto, 1989); en cambio, observadas en términos sistémicos, relacionales y diacrónicos, muchas de estas prácticas pueden resignificarse. Diremos entonces que aumenta la población que presenta "dilación en sus estudios" (Stasiejko et al., 2013), para cuya identificación elaboramos la definición específica del fenómeno donde "el estudiante, matriculado en un determinado plan de estudios, no aprueba la cantidad de materias previstas por año, o en el tiempo teórico de la carrera, retrasando el egreso" (Giovine y Antolín Solache, 2019: 69).

Este abordaje nos permite incorporar a los estudiantes que, dejando de cursar por algunos años, no abandonan su pretensión de titularse retomando al tiempo, y a quienes cambian de carrera y/o de universidad, como una manera de sostener sus estudios dentro del nivel.

Presentando a Tinto como un modelo teórico, Fonseca y García (2016) desde la perspectiva organizacional, sistematizan cinco enfoques sobre la permanencia y dan cuenta de una insuficiente incorporación de variables pedagógicas y una escasez de investigaciones mixtas en el estudio de un fenómeno tan complejo y multivariado, como es el de la permanencia en los estudios universitarios. En este marco, nuestra investigación asume un enfoque principalmente sociológico, considerando a la vez las dimensiones económica, organizacional e interaccionista (op. cit.), al tiempo que comenzamos a explorar algunas variables pedagógicas.

Identificamos que esta población que presenta dilación en sus estudios, establece lo que hemos llamado estrategias de permanencia en el nivel (Giovine y Antolín Solache, 2019). Las estrategias de permanencia, en tanto estrategias de reproducción social, en Bourdieu dependen del volumen, la estructura del capital que hay que reproducir y de su trayectoria histórica, del estado de la relación de fuerzas entre las clases, de los habitus incorporados y del estado del sistema de los instrumentos de reproducción disponibles. El concepto de instrumentos de reproducción social es relacional. "Se trata de los distintos mecanismos institucionalizados o no (como el mercado de trabajo, el mercado escolar, etcétera) que constituyen las formas que cobran las condiciones estructurales a través del tiempo, como posibilidades e imposibilidades objetivas para las familias" (Gutierrez, 2007: 21).

El concepto de estrategias de reproducción social de Bourdieu (1988), nos permite definir como estrategias de permanencia en la universidad a todo conjunto de prácticas, que pueden aparecer como muy diferentes unas de otras, por medio de las cuales los individuos y las familias tienden, consciente o inconscientemente, a conservar el nivel universitario alcanzado frente a una situación de dilación de los 
estudios, y correlativamente a mantener o mejorar su posición en la estructura de relaciones de clases.

Dentro de este conjunto de prácticas hemos identificado, mediante entrevistas, dos grandes grupos que denominamos estrategias de sustitución y estrategias de persistencia, que se articulan según el volumen y la composición de capital que disponga la familia. No son necesariamente excluyentes, ya que pueden presentarse ambas: generalmente se establecen estrategias de persistencia primero y luego, si no se obtienen los resultados esperados, se articulan estrategias de sustitución (Giovine y Antolín Solache, 2019). Frente a la dilación de los estudios universitarios denominamos a éstas como el conjunto de prácticas muy diversas entre sí, no necesariamente conscientes ni planificadas, por las cuales los estudiantes y sus familias optan por el cambio de carrera universitaria y/o el cambio de universidad, buscando condiciones más favorables para el cursado y para el egreso (Giovine y Antolín Solache, 2019).

De acuerdo con los recursos que tengan disponibles y el estado de los instrumentos de reproducción, las familias pueden articular estrategias de persistencia, en pos del sostenimiento del cursado en la misma titulación, con un ritmo e intensidad diferente del establecido en el plan de estudios, o intentar un cambio más agudo articulando estrategias de sustitución.

La mirada relacional del sistema es fundamental para comprender que, aquello que visto desde una titulación particular implica desgranamiento y deserción, cuando se considera desde el conjunto de carreras puede ser resignificado como estrategia de sustitución en el nivel universitario.

Para ello los estudiantes y sus familias consideran la continuación de las mismas carreras en otras universidades o carreras afines que sean de menor exigencia, en las mismas o en otras universidades, que impliquen menos años de estudio y donde se reconozcan las materias del trayecto académico recorrido o con mayor cercanía a la institución y a los docentes.
Si el estudiante cuenta con los recursos necesarios, dispuestos por su familia o gracias a un empleo, busca continuar sus estudios en universidades privadas. Los estudiantes con menor volumen total de capital, o que no cuenten con un empleo para pagar sus estudios en una universidad privada, buscan el cambio dentro de las universidades estatales. Otro grupo continuará sus estudios fuera del ámbito universitario, en carreras terciarias o en circuitos de formación profesional (Giovine y Antolín Solache, 2019). No desconocemos la relevancia de estos últimos trayectos, sin embargo, en este estudio nos ocuparemos sólo de las estrategias de permanencia en la universidad, quedando para otras investigaciones la reconstrucción de la oferta mencionada.

\section{La clasificación de las titulaciones}

El abordaje de los instrumentos de reproducción social universitaria encuentra en las titulaciones de las distintas instituciones un indicador potente, ya que reúnen características de las cuatro dimensiones de la permanencia en los estudios mencionadas por Fonseca y García (2016).

Una de las más estudiadas (Clark, 1991; Dirié, 2001; Fernandez Lamarra, 2018) es el campo de formación en que se adscribe cada titulación; por ello, para la sistematización de las titulaciones adoptamos el clasificador de CEPRES (Consejos Regionales de Planificación de la Educación Superior), que tiene mayor nivel de desagregación y se organiza según los campos de inserción profesional de los graduados (Tavela y Catino, 2018). La necesidad de ganar en discriminación en Córdoba requirió desagregar el campo Artes y humanidades y distinguir Educación física de Docencia y educación. De esta manera el clasificador queda conformado por 14 campos de formación.

Por universidad y campo de formación, las titulaciones en Córdoba se distribuyen de la siguiente manera:

La UNC ofrece 124 titulaciones en 12 de los 14 campos de formación; los únicos campos que no cubre son 
Educación física y Preservación de recursos naturales y medioambiente. Además, es la principal institución que cuenta con titulaciones en el campo Conocimientos naturales, fisicos y matemáticos, con 11 de las 12 dictadas en Córdoba, que es la que abarca más campos.

La UTN, Facultad Regional Córdoba, con 19 titulaciones en cuatro campos de formación, concentra su oferta en Procesos productivos, diseño y construcciones, con orientación definida hacia las carreras para la producción y las telecomunicaciones.

La UPC ofrece 21 titulaciones en siete de los 14 campos de formación. Las carreras, en su etapa en educación superior, complementaban la oferta existente en las universidades. Actualmente, muchas de ellas sólo se siguen dictando en esta institución, por ejemplo el profesorado en Educación física y la licenciatura en Composición coreográfica.

El IUA brinda una oferta de 14 titulaciones, la mitad de ellas en los campos disciplinares Procesos productivos, diseño y construcciones y Tecnología de la información y la comunicación, propios de su especificidad institucional. La otra mitad pertenece al campo Administración y Comercio.

Entre las universidades privadas, la UCG dicta 48 titulaciones que abarcan 10 campos de formación, quedando sin cubrir Artes, Educación física, Preservación de recursos naturales y medioambiente y Servicios turísticos, hoteleros y gastronómicos.
La UBP brinda 48 titulaciones en nueve de los 14 campos de formación. Si bien es una oferta amplia, no cubre los campos de Artes, Humanidades, Conocimientos naturales, físicos y matemáticos, Producción agropecuaria, alimentaria y salud animal y Salud humana.

Lo mismo sucede con la oferta de la UES21, con 63 titulaciones, que exceptúan Artes, Conocimientos naturales, físicos y matemáticos, Educación física, Humanidades y Producción agropecuaria, alimentaria y salud animal.

Finalmente, el IUCBC, ofrecía en 2017 sólo una titulación, en el campo Salud humana.

Las universidades estatales concentran las titulaciones de los campos de Artes, Conocimientos naturales, físicos y matemáticos, Humanidades y Procesos productivos, diseño y construcciones. Por su parte las universidades privadas agrupan la mayoría de titulaciones en los campos Administración y comercio, Derecho y justicia, Docencia y educación, Preservación de recursos naturales y medioambiente y Servicios turísticos, hoteleros y gastronómicos. La oferta de titulaciones se encuentra relativamente equilibrada en los campos Procesos sociales, culturales y políticos, Producción agropecuaria y alimentaria, y salud animal, Salud humana y Tecnología de la información y la comunicación. 


\section{Gráfico 4. Total de titulaciones, por campo de formación, universidad y sector de gestión,} Gran Córdoba, 2017

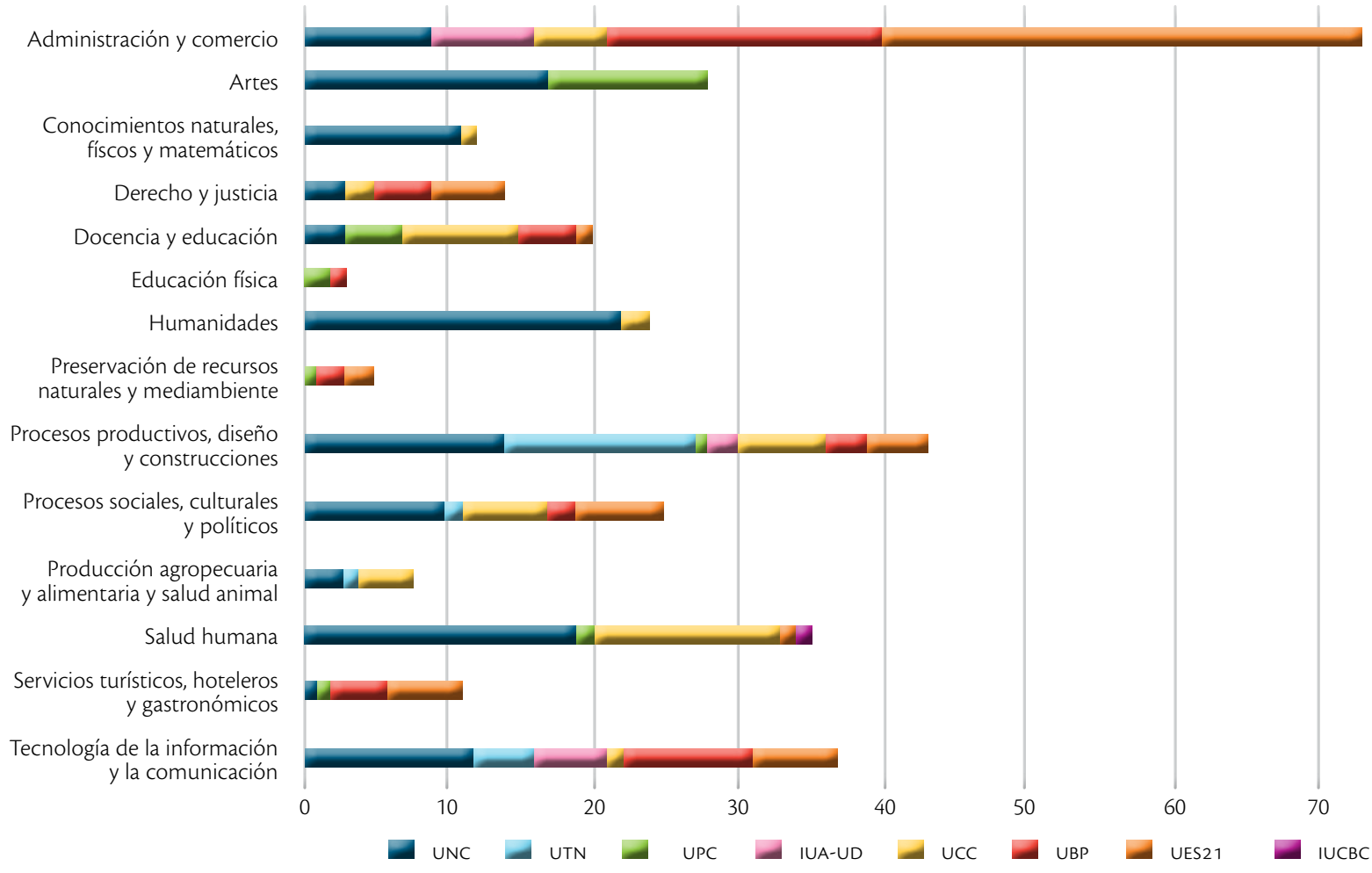

Fuente: elaboración propia en base a datos SPU - Ministerio de Educación.

\section{El espacio de las titulaciones universitarias en Córdoba}

Hemos dicho hasta aquí que las familias ponen a jugar sus capitales diferenciales para afrontar la situación de dilación de los estudios y diseñar estrategias para superarla. En este marco evalúan "opciones" considerando las condiciones de la oferta. Es por ello que reconstruimos la oferta universitaria en Gran Córdoba en tanto condicionante y habilitante para las estrategias de sustitución.

En función de los datos provistos por la $\mathrm{SPU}^{4}$ correspondientes a las titulaciones universitarias vigentes para el ciclo lectivo 2017, en las universidades con sede en la capital de la provincia, construimos una base de datos específica a la que aplicamos un Análisis de Correspondencias Múltiples (ACM) y luego una Clasificación Jerárquica Ascendente (CJA), mediante el software spad (Sistema Portable de Análisis de Datos).

Hemos optado por esta técnica, la que utilizara Pierre Bourdieu en sus estudios (por ejemplo, 1988), porque permite sostener la complejidad (multidimensionalidad) del análisis relacional durante todo el procesamiento de los datos, a la vez que posibilita la construcción de clases (clusters) en función de la posición que ocupan las titulaciones en el espacio de sus atributos.

Para ello, consideramos un conjunto de variables activas que inciden en la deformación de la nube de datos (Moscoloni, 2011) y otro conjunto de variables, denominadas ilustrativas, que aparecen representadas en dicha nube para contribuir a la descripción de

\footnotetext{
${ }^{4}$ De un total de las 415 titulaciones, dimos por perdidos los 77 casos que no presentaban datos de matrícula para ninguna de las variables: nuevos inscritos, reinscritos, estudiantes y egresados.
} 
las clases, pero no inciden en su deformación. Dentro de las variables activas identificamos tres grandes grupos, uno referido a los establecimientos, otro al currículum de las titulaciones y el último relativo a su matrícula. En el primero reunimos las variables Universidad y Régimen. En el segundo, las características curriculares: Nivel de la titulación, Modalidad de dictado, Tipo de carrera, Duración de las materias (ilustrativa), Total de años de la titulación, Campo de formación, Alcance de la titulación y Estado de la titulación. En el tercer agrupamiento, encontramos las variables que representan la matrícula de cada titulación bajo su forma de: Nuevos inscritos, Reinscritos, Estudiantes (ilustrativa) y Egresados. ${ }^{5}$ Las categorías de las variables activas se presentan en la tabla 2 .

Tabla 2. Categorías de las variables consideradas en la construcción del espacio de las titulaciones

\begin{tabular}{|c|c|c|}
\hline Dimensión & Variable & Categorías \\
\hline \multirow{2}{*}{ 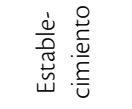 } & Universidad & UNC - UTN - IUA/UD - UPC - UCC - UES21 - IUCBC \\
\hline & Régimen & Estatal - Privado \\
\hline \multirow{8}{*}{ 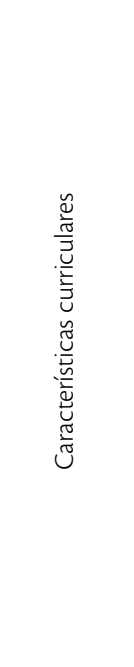 } & Nivel & Grado - Pregrado \\
\hline & Campos de formación & $\begin{array}{l}\text { 1) Administración y comercio, 2) Artes, 3) Conocimientos naturales, físicos y matemáticos, 4) } \\
\text { Derecho y justicia, 5) Docencia y educación, 6) Educación Física, 7) Humanidades, 8) Preservación } \\
\text { de recursos naturales y medioambiente, 9) Procesos productivos, diseño y construcciones, 10) } \\
\text { Procesos sociales, culturales y políticos, 11) Producción agropecuaria y alimentaria, y salud animal, } \\
\text { 12) Salud humana, 13) Servicios turísticos, hoteleros y gastronómicos y 14) Tecnología de la } \\
\text { información y la comunicación. }\end{array}$ \\
\hline & Modalidad & Presencial - A distancia \\
\hline & Estado de la titulación & Establecida - Nueva - En cierre \\
\hline & Tipo de carrera & Completa - Título intermedio - Complementaria \\
\hline & Alcance & Profesional - Profesorado - Tecnicatura \\
\hline & Tipo de duración & Anual - Semestral - Cuatrimestral \\
\hline & Total Años Nº & $1-1.5-2-2.5-3-4-4.5-5-5.5-6$ \\
\hline \multirow{3}{*}{ 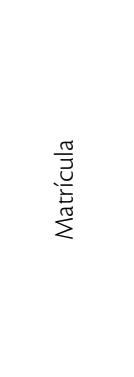 } & $\begin{array}{l}\text { Estudiantes (Total) } \\
\text { Egresados (Total) } \\
\text { Reinscritos (Total y por edad) } \\
\text { Nuevos inscritos (Total y por edad) }\end{array}$ & Nulo - Bajo - Medio - Alto \\
\hline & RatEst/Egr & Sin egresados - Bajo - Medio - Alto \\
\hline & $\begin{array}{l}\text { Sexo } \\
\text { Estudiantes } \\
\text { Nuevos inscritos } \\
\text { Reinscritos egresados }\end{array}$ & Mayoría mujeres - Mayoría varones - Equidad - Nulo \\
\hline
\end{tabular}

Fuente: elaboración propia en base a datos de la SPU.

\footnotetext{
${ }^{5}$ Incluimos dentro del grupo de variables curriculares tres creadas específicamente para este estudio, que buscan capturar algunos de los movimientos en la dinámica universitaria que no encontramos en el registro estadístico oficial. La variable Tipo de carrera identifica si la titulación es Intermedia, Completa o Complementaria de una de las anteriores o de una titulación de nivel superior no universitario. La variable Alcance de la titulación se apoya en las incumbencias de los títulos, para definir las categorías Profesional, Tecnicatura y
} 


\section{Las clases de las titulaciones en Córdoba}

A continuación presentamos el espacio de las titulaciones de Córdoba 2017 (gráfico 4, 5 y 6). Dicho espacio resume la dispersión de los datos. En los gráficos mostramos las tres dimensiones con mayor porcentaje de inercia, que recalculada según la ecuación de Benzécri acumula el $60 \%$ de la inercia total.

El primer factor está caracterizado principalmente por la duración de las titulaciones, yendo de 1 año en el tercer cuadrante a la izquierda, a 5.5 años en el cuarto cuadrante a la derecha, oponiendo las carreras de menor a las de mayor duración. El segundo factor es más complejo y opone con menor intensidad el régimen, el nivel, la modalidad de dictado y la proporción de estudiantes por sexo en las variables de matrícula.

El tercer factor, por su parte, opone las titulaciones con un total de estudiantes alto de las carreras, frente a los que no cuentan con estudiantes, y el campo Derecho y justicia a los campos Educación física y Artes. También distingue las titulaciones nuevas de las establecidas y en cierre, y los títulos intermedios de las carreras completas y complementarias. Esta dimensión opone a la UPC de la UES21 y la UBP.

Para construir las clases de las titulaciones consideramos tres cortes en el dendrograma (gráfico 1 en el Anexo) que, al ser la clasificación jerárquica y ascendente, permitieron definir la cantidad de grupos y subgrupos de titulaciones: primero un corte de dos clases, luego de tres y finalmente de seis (fracciones). ${ }^{6}$

La primera división da por resultado dos grandes clases: un grupo que concentra el $86 \%$ de las titulaciones, y un segundo grupo, que se mantendrá homogéneo en la subdivisión siguiente y se ubica en el primer cuadrante del gráfico 5, concentrando el $14 \%$ del total.

Las modalidades que conforman este segundo grupo son titulaciones de pregrado, o títulos intermedios, que presentan algunas de sus variables de matrícula con valor 0 (matrícula nula), ya sea porque las titulaciones asociadas son nuevas y por lo tanto tienen solamente nuevos inscritos, sin contar con reinscritos y egresados, o porque son titulaciones que están en cierre, como parte de un proceso de cambio en la oferta y por ende no cuentan con nuevos inscritos ni con reinscritos, sino sólo con egresados. La clase más numerosa, asocia titulaciones de grado, de 5 años de duración, de alcance profesional, ya establecidas y completas.

Como resultado del segundo corte, esta última clase se fracciona en dos grupos que concentran, respectivamente, el 55 (fracción 1/3) y el 31\% (2/3) de las titulaciones. El rasgo que más fuertemente las opone, a la primera en el cuarto cuadrante y a la segunda en el primero, es la modalidad de dictado, presencial o a distancia, respectivamente. La fracción más grande asocia, además, las titulaciones de grado, que se dictan en universidades estatales, completas, establecidas y de alcance profesional. La fracción menor se caracteriza por incluir titulaciones complementarias y de pregrado, en el sector privado, a distancia y organizadas en cuatrimestres. La fracción $3 / 3$ se mantiene igual.

\footnotetext{
Profesorado. Finalmente, con la variable Estado de la titulación describimos si la titulación es Nueva, ya está Establecida o se encuentra En cierre. Convertimos las variables de matrícula en categóricas ordinales. Así, a cada titulación le corresponde un valor (nulo, bajo, medio o alto) de acuerdo a la posición que ocupa (cuartil) en la distribución de los datos de cada variable para todas las titulaciones. A cada una de las variables de matrícula, excepto Egresados, se les sometió a una categorización en función de la proporción de varones respecto del total de estudiantes. De este modo, se determinó si la titulación tenía mayoría de varones, mayoría de mujeres o distribución equitativa entre sexos. Para categorizar las variables Nuevos inscritos y Reinscritos según edad construimos cuatro agrupamientos, de 17 a 23, de 24 a 29, de 30 a 39 y de 40 y más años de edad. Con esto buscamos identificar cómo se distribuye la matrícula de las titulaciones, entre los grupos más jóvenes o los de mayor edad. Para cada uno de estos grupos utilizamos las categorías nulo, bajo, medio o alto en función de su participación en el total. Finalmente se construyó una nueva variable para expresar la relación entre Estudiantes y Egresados, un índice simple que llamamos RatEst/Egr, también categorizada en nulo, bajo, medio o alto de acuerdo con la posición en la distribución (cuartiles).

${ }^{6}$ En los gráficos 5 y 6 las clases están representadas por medio de círculos.
} 


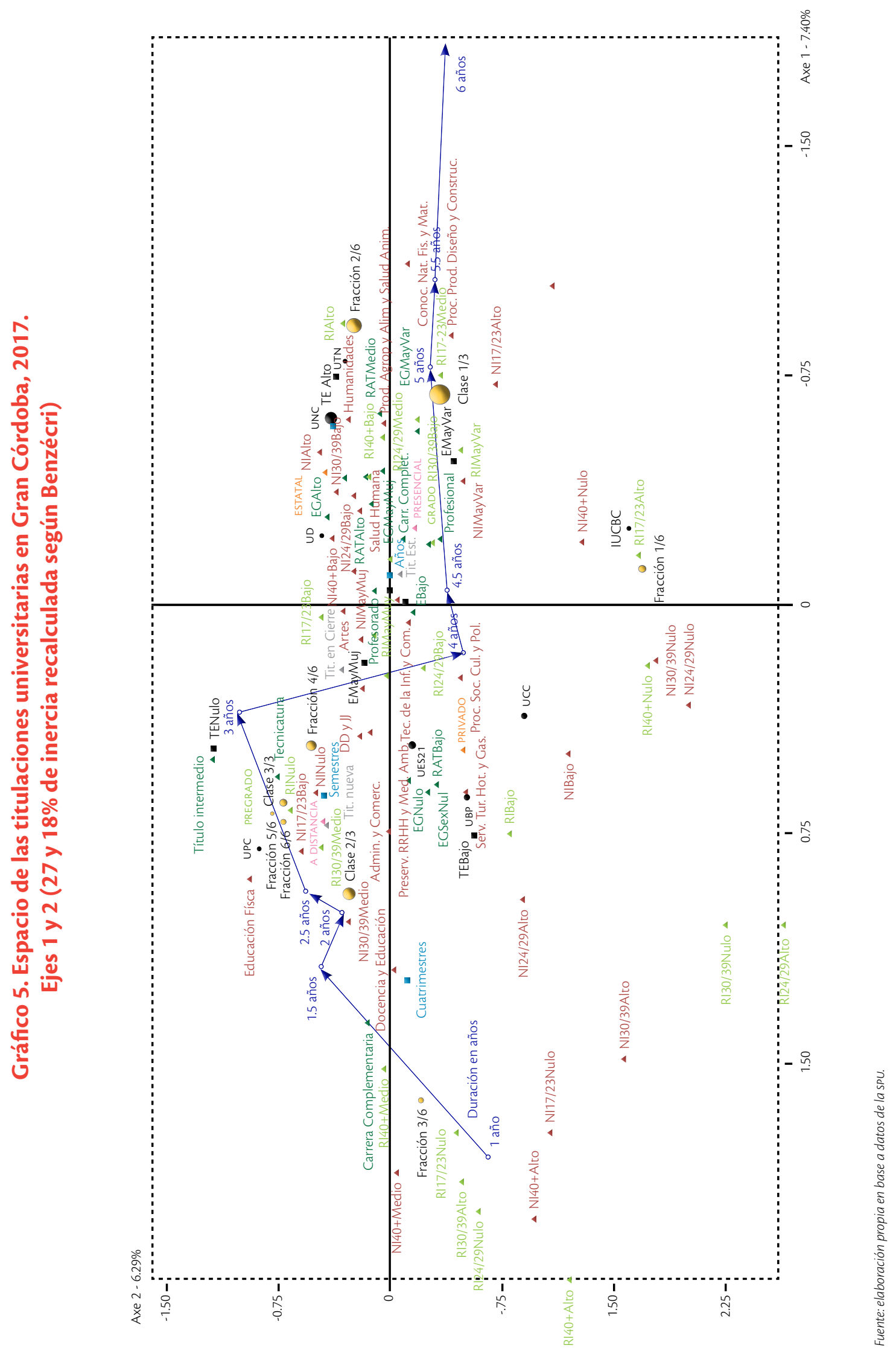




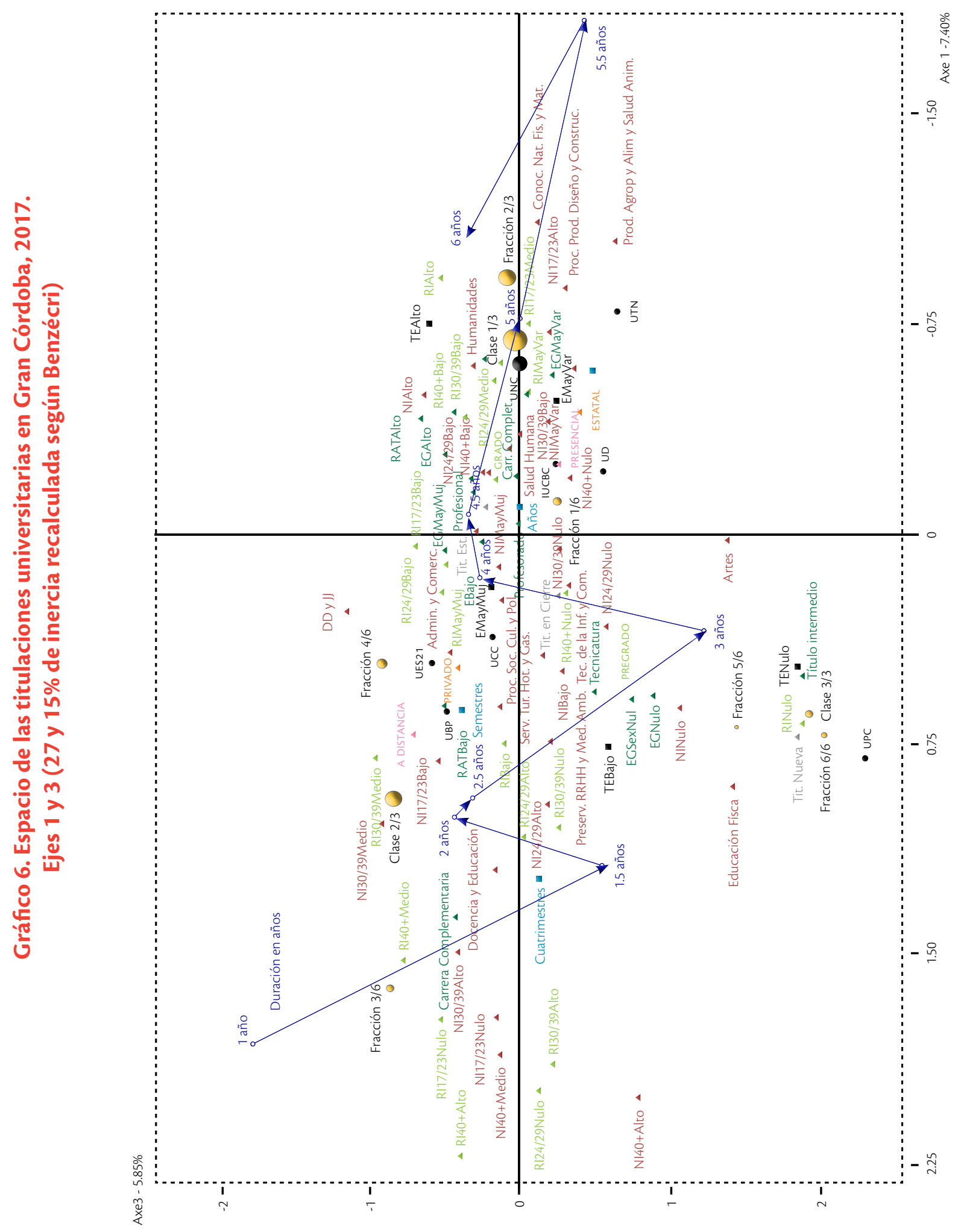


Para ganar en precisión en la descripción, se realizó un tercer corte, obteniendo de cada una de las tres grandes clases, dos fracciones. La clase 1/3, que reúne al $55 \%$ de las titulaciones, se divide en dos fracciones que aglutinan, respectivamente, el 16 y el 39\%. La fracción que denominamos Titulaciones completas en el sector privado (1/6), se caracteriza por titulaciones completas, de grado, presenciales, de alcance profesional, de régimen privado, de cuatro años de duración y asociadas a la UCC. Se caracteriza también por nuevos inscritos y reinscritos jóvenes y una baja cantidad de estudiantes por titulación en su mayoría varones.

La fracción Titulaciones completas en el sector estatal $(2 / 6)$ asocia titulaciones presenciales, de grado, completas, de 5 años de duración, estructuradas en años, de régimen estatal, alcance profesorado, asociadas a la UNC con mayor fuerza y a la UTN en segundo lugar. En los campos Humanidades, Conocimientos naturales físicos y matemáticos y Procesos productivos, diseño y construcciones. Son titulaciones con gran cantidad de estudiantes y de egresados, en ambos casos jóvenes (17 a 23 y 24 a 29 años), y una ratio medio-alta.

La clase 2/3 se divide en dos fracciones, una que asocia al $9 \%$ de las titulaciones y otra que reúne el $22 \%$. La fracción 3/6, que llamamos Docentes perfeccionándose en universidades privadas, está caracterizada por titulaciones complementarias, de 2 años de duración, dictadas bajo el sector de gestión privado. Están organizadas en cuatrimestres, con duración de entre tres y cuatro cuatrimestres, en el campo Docencia y educación. Son titulaciones asociadas principalmente a la UCG, nuevos inscritos y reinscritos mayores (30 a 39 y 40 y más años) y baja cantidad de reinscritos. Tanto reinscritos como egresados ocupan las categorías de mayor edad y, en todos los casos, la matrícula tiene mayoría de mujeres. La relación entre estudiantes y egresados es baja.

La fracción 4/6, Mayores en Administración y comercio y carreras a distancia, agrupa titulaciones de pregrado, con alcance tecnicatura, modalidad a distancia y régimen privado, específicamente asociadas a UES21 y UBP. Son titulaciones completas que se dictan en 4 y 2.5 años, predominantemente en el campo Administración y comercio. Se caracteriza por tener estudiantes mayores, un alto total de nuevos inscritos y una alta relación egresados/estudiantes, asociada a un alto total de egresados. Tanto en Estudiantes como en Nuevos inscritos y Reinscritos no predominan ni varones ni mujeres.

La tercera clase, aquella que se diferenció primero, aglutina dos fracciones que concentran el 5 y el $9 \%$ de las titulaciones respectivamente. La fracción que denominamos Las tecnicaturas que desaparecen (5/6), agrupa titulaciones intermedias, de pregrado, con alcance de tecnicatura, de tres años de duración, bajo el régimen estatal y el campo Tecnología de la información y comunicación. Se dictan principalmente en la UD. Asocia titulaciones que no tienen Nuevos inscritos ni Reinscritos, es decir que agrupa títulos intermedios (no tienen matrícula propia, los estudiantes se matriculan para el título final) o que ya no tienen cursado y sólo quedan alumnos que van egresando.

La fracción 6/6, Nuevas ofertas, se caracteriza por titulaciones nuevas, de régimen estatal, modalidad presencial, organizadas en cuatrimestres, con una duración de entre 1.5 y tres años. Son titulaciones de nivel de pregrado, alcance tecnicatura, en los campos Docencia y educación y Artes, principalmente de la UPC. Al ser recientes, no poseen reinscritos ni egresados pero sí un volumen medio de nuevos inscritos, en su mayoría mujeres.

El ACM y la CJA nos permitieron conformar clases y fracciones, y representar de un modo sintético las principales desigualdades que operan entre las titulaciones y sus atributos. De este modo, podemos reconstruir el estado de los instrumentos de reproducción que hacen posible las estrategias de permanencia en el nivel y particularmente las estrategias de sustitución, en tanto espacio de potencialidades y limitaciones (Giddens, 1993). 


\section{Los condicionamientos y las estrategias de sustitución}

Según sea la amplitud de un campo de formación en Córdoba, en términos de oferta, los alumnos tendrán más o menos opciones para establecer estrategias de sustitución.

Del mismo modo que Accinelli et al. (2016) diferencian a las universidades estatales según su antigüedad, masividad y vínculo con los estudiantes, nosotros detectamos similares especificidades entre las titulaciones de las universidades estatales tradicionales y las titulaciones de las universidades privadas cordobesas.

El volumen y estructura del capital del que disponen las familias es condicionante para las estrategias de sustitución, particularmente los recursos económicos cuando se produce el cambio a una universidad privada. Así, las estrategias de sustitución se establecen predominantemente en familias de mayor volumen de capital. No obstante, hemos observado un gran esfuerzo de las familias de menor volumen de capital por acceder a una oferta que tenga mejores condiciones de cursado (Giovine y Antolín Solache, 2019). Y, simultáneamente, el esfuerzo de algunas instituciones por facilitar las estrategias de sustitución.

De esta manera, las estrategias de sustitución estarán condicionadas por otras variables, estructurales, por ejemplo el régimen de la carrera, estatal o privado, que conlleva el pago de aranceles; el nivel de la titulación, que puede significar muchas veces la renuncia a los títulos de grado por los de pregrado; la modalidad de dictado, que permite cursar de manera presencial o a distancia. También condicionan el cambio de titulación la duración de los estudios, con ofertas más cortas, incluso con el mismo alcance.

Para ejemplificar este espacio de posibilidades hemos seleccionado algunos ejemplos. El campo de formación con mayor oferta de titulaciones entre las universidades de Gran Córdoba es Administración y comercio, con 73 titulaciones. De éstas, el 45\% se dicta en la UES21, el 26\% en UBP, $12 \%$ en UNC,
$10 \%$ en IUA y $7 \%$ en UCC. Un estudiante que curse la licenciatura en Administración en la UNC (fracción 2/6) y presente dilación en sus estudios no tiene ofertas equivalentes, sin pagar aranceles. Puede cambiar a una titulación del mismo campo en la misma universidad pero en el nivel de pregrado como son las tecnicaturas superior universitaria en Administración de cooperativas y mutuales (2/6), de cursado presencial, o en Relaciones públicas, que se cursa a distancia (6/6).

Para mantener el nivel en una universidad estatal, puede intentar continuar con la misma titulación (2/6) con modalidad a distancia en el IUA, aunque tendrá que afrontar los aranceles. En el sector privado encontrará la misma licenciatura presencial (1/6) y a distancia (4/6) en la UBP y en el pregrado puede intentar en la tecnicatura universitaria en Gestión de sociedades cooperativas (3/6). Finalmente, en la UES21 puede cursar la misma titulación que en la UNC en ambas modalidades, presencial (2/6) y a distancia (4/6). O también en el grado y con cierta especificación, la licenciatura en Administración agraria, presencial (1/6) o a distancia (4/6), entre otras. En tanto a nivel de pregrado, se ofrecen las tecnicaturas en Administración y gestión tributaria y en Políticas públicas, ambas a distancia (4/6).

En el campo de formación Conocimientos naturales, fisicos y matemáticos (nueve titulaciones, ocho en la UNC), un estudiante de la licenciatura en Matemáticas $(2 / 6)$ en la UNC tiene aún menos posibilidades de sustitución: todo cambio implicará desplazamiento de la especificidad disciplinar, por ejemplo hacia las Ciencias de la computación, de grado (2/6) o pregrado $(5 / 6)$ o hacia el profesorado de Matemáticas (2/6). En este último caso cambia también de campo de formación, a Docencia y educación.

Por su parte, los estudiantes de Medicina en Gran Córdoba pueden cursar en la UNG (2/6), la UCG $(2 / 6)$ y el IUCBC (1/6), siempre en nivel de grado y modalidad presencial. Éstas son las únicas tres opciones disponibles en la misma titulación. El campo 
Salud humana cuenta con 35 titulaciones en total, distribuidas entre UNC (54\%), UCG (37\%) y UPC, UES2 1 y IUCBC (3\%). Los estudiantes pueden optar por cambiar a otra titulación de grado como la licenciatura en Kinesiología y fisioterapia (2/6). Si el estudiante prefiere cambiar de nivel puede optar por la titulación de Enfermero (5/6), en la UNC o en la UCG la titulación de Instrumentador quirúrgico universitario (5/6), ambas presenciales.

Este análisis nos permite ver cómo los campos de formación, con sus variables asociadas, en su despliegue en el espacio de las titulaciones de Córdoba, generan las condiciones de posibilidad/imposibilidad para las estrategias de sustitución.

\section{Conclusiones}

Este artículo tiene como precedente otro estudio donde abordamos la expansión de la matrícula universitaria en Argentina y Córdoba, producto de las políticas de democratización del acceso y de retención de los estudiantes, lo que no se vio reflejado en el crecimiento proporcional de los egresos. Esto dio por resultado un gran volumen de reinscritos netos, que conduce a la problemática de la dilación de los estudios universitarios. Para abordar este tópico, en el marco de un análisis por clases sociales, propusimos la categoría analítica de estrategias de permanencia y dentro de ella, las estrategias de persistencia y de sustitución.

En este artículo exploramos el acceso y el egreso de la población de Córdoba por quintiles de ingreso familiar, pudiendo observar que el primer quintil de ingreso sigue sin acceder a la universidad, pero el segundo, tercer y cuarto quintil protagonizan una mejora en el acceso que no se replica en el egreso, dando lugar a mayores condiciones para la dilación de los estudios y para estrategias de sustitución diferenciales según el volumen y la estructura del capital de las familias.

Entendemos que dichas estrategias están condicionadas/habilitadas por el volumen, estructura y trayectoria del capital que disponen los estudiantes y sus familias y por el estado de los instrumentos de reproducción universitarios disponibles, donde la diversificación de las disciplinas por el crecimiento de las especialidades, mediada por las particulares formas de organización de las universidades, estatales y privadas, da lugar a una configuración jerárquica entre éstas, que expresa las disputas en el sistema de la oferta y en el mercado de trabajo.

En función de esto, clasificamos las titulaciones provistas por la Secretaría de Políticas Universitarias según campos de formación y mediante una técnica de ACM y CJA, construimos el espacio de las titulaciones universitarias de grado y pregrado, donde las estrategias de permanencia y en particular las de sustitución, tienen lugar.

Así, hemos reconstruido de un modo complejo, relacional y multidimensional el sistema de titulaciones de grado y pregrado de Córdoba, en tanto se constituye en un espacio de posibilidades (potencialidades) y limitaciones para las estrategias de sustitución frente a la dilación en los estudios, que adicionalmente en Argentina tiene un valor específico, dado que son las titulaciones de pregrado y grado, más que las de posgrado, las que establecen las principales incumbencias profesionales.

Los hallazgos han mostrado múltiples potencialidades. En lo concerniente a nuestro objeto de estudio hemos podido construir clases y fracciones de clase de titulaciones e identificar, a partir de los campos de formación establecidos previamente, los espacios de posibilidades estructurales que posee el sistema para que las familias establezcan estrategias de sustitución. Así lo ejemplificamos para carreras como Administración de empresas, Medicina o Matemáticas.

La construcción del espacio de desigualdades en la oferta de las titulaciones de Córdoba ha permitido observar cómo funciona un sistema complejo de oferta educativa, donde el Estado se hace cargo casi exclusivamente de áreas como las ciencias básicas, 
las humanidades y las artes y el sector privado ha ganado terreno en áreas como la administración o las ingenierías. Incluso se identifica un nuevo espacio de disputa en el campo de la salud humana, donde hasta hace muy pocos años el Estado prácticamente tenía el monopolio de la oferta.

Además de la desigualdad asociada a la posición de las familias en el espacio social, desigualdades de origen, se agregan los efectos no deseados de una apertura también desigual, que se manifiestan en el acceso y la permanencia en las universidades, pero que no ha implicado aún una democratización en el egreso.

Este proceso expone a las familias con estudiantes que presentan dilación en sus estudios a otra desigualdad, la que opera en las estrategias de permanencia.

\section{Referencias}

Accinelli, Adriana, Martha Losio y Alejandra Macri (2016), "Acceso, rezago, deserción y permanencia de estudiantes en las universidades del Conurbano Bonaerense: análisis a partir de datos oficiales", Debate universitario, num. 5, vol. 9, Buenos Aires, PPCT, pp. 33-52, http:// ppct.caicyt.gov.ar/index.php/debate-universitario/ article/view/12823 [Consulta: septiembre de 2019].

Alonso, Laura (2015, junio), "Calidad e inclusión en la educación superior", Ponencia presentada en el Seminario Internacional Experiencias y Perspectivas de Evaluación y Acreditación Universitaria en Iberoamérica, Buenos Aires, Ministerio de Educación, http://www.coneau.gob.ar/archivos/pdfSeminario/ SeminarioCONEAU_PresentacionLauraAlonso.pdf [Consulta: septiembre de 2019].

Antolín Solache, Ana y Manuel Giovine (2019), "Estrategias de sustitución e instrumentos de reproducción en estudiantes universitarios de Córdoba-Argentina, en las últimas décadas", Ponencia presentada en el III Coloquio de investigación educativa en Argentina, Buenos Aires, junio, https://investigacioneducativacoloquio.wordpress.
Algunas familias podrán establecer estrategias de sustitución, en ocasiones bajo grandes sacrificios económicos, y otras se verán en situación de sostener estrategias de persistencia, pudiendo darse el caso de estudiantes que llevan muchos años en la misma carrera, viviendo una suerte de trampa de Sísifo, con elevados costos personales y sociales, no siempre reconocidos. En este marco conocer el estado del sistema de instrumentos de reproducción es clave para entender cómo opera la desigualdad educativa.

Esta última cuestión abre múltiples dimensiones para nuevas investigaciones. Nuestro próximo objetivo consistirá en dar cuenta de los sentidos vividos asociados a las estrategias de persistencia y sustitución de los estudiantes con dilación en los estudios universitarios de Córdoba. com/ejes-grupos-de-trabajo-2019/.

Bourdieu, Pierre (1988), La distinción. Criterio y bases del gusto, Madrid, Taurus.

Clark, Burton (1991), El sistema de educación superior, Nueva Imagen, México.

Dirección General De Planeamiento, Información y Evaluación Educativa (2017), Estadísticas de la Educación 2017, Córdoba, Ministerio de Educación, https:// www.cba.gov.ar/informacion-y-estadistica-educativa/ [Consulta: septiembre de 2019].

Dirié, Cristina y equipo (2001), Mapa de la oferta de educación superior en la Argentina del 2000, Buenos Aires, CONEDUS, http://www.oei.es/homologaciones/INFORMEFinal. pdf [Consulta: junio de 2005].

Fernández Lamarra, Norberto (2018), La educación superior universitaria en Argentina: Situación actual en el contexto regional, Buenos Aires, Sáenz Peña/UNTREF, http:// www.bnm.me.gov.ar/gigal/documentos/EL006310. pdf [Consulta: marzo de 2019].

Fonseca, Gonzalo y Fernando García (2016), "Permanencia y abandono de estudios en estudiantes universitarios: 
un análisis desde la teoría organizacional", Revista de Educación Superior, vol. 45, num. 179, pp. 25-39, http:// resu.anuies.mx/ojs/index.php/resu/article/view/115 [Consulta: septiembre de 2019].

Giovine, Manuel y Ana Antolín Solache (2019), "Estrategias de permanencia y desigualdad social en estudiantes universitarios de Córdoba-Argentina en la actualidad", Revista de la Educación Superior, vol. 48, num. 192, pp. 67-92, http://resu.anuies.mx/ojs/index.php/ resu/article/view/932.

García de Fanelli, Ana María (2017), "Políticas públicas ante la masificación de la educación universitaria: el reto de elevar la graduación, garantizando la inclusión y la calidad", en Carlos Marquis (ed.), La agenda universitaria III. Propuestas de políticas y acciones, Buenos Aires, Universidad de Palermo, pp. (s/d).

Giddens, Anthony (1993), Las nuevas reglas del método sociológico, Buenos Aires, Amorrortu.

Giovine, Manuel y Antolín Solache, Ana (2018, diciembre), "Estrategias de permanencia y desigualdad social en estudiantes universitarios de Córdoba-Argentina en la actualidad". Ponencia presentada en las X Fornadas de Sociología de la Universidad Nacional de La Plata. Facultad de Humanidades y Ciencias de la Educación, La Plata, Argentina <http:// jornadassociologia.fahce.unlp.edu.ar/x-jornadas $>$.

Giovine, Manuel (2015), "Condicionamientos educativos de los sectores dominantes en Gran Córdoba: cambios y transformaciones 2003-2011", Revista de la Educación Superior, vol. XLV, núm. 177, pp. 119-46.

Gutiérrez, Alicia Beatriz (2007), "Herramientas teóricometodológicas de un análisis relacional para los estudios de la pobreza", Ciencia, Docencia y Tecnología, vol. XVIII, núm. 35, pp. 15-33.

Gutiérrez, Alicia Beatriz y Manuel Giovine (2017), "Access to higher education and the reproduction of inequalities in Córdoba, Argentina”, Rassegna Italiana di Sociologia, vol. 58, núm. 2, pp. 381-418.

Instituto de Estadística de la UNESCO (2015), Manual Operativo CINE 2011: directrices para clasificar programas nacionales de educación y certificaciones relacionadas, Montreal, Instituto de Estadística de la UNESGO, DOI: http://dx.doi.org/10.15220/978-929189-181-8-spa.

INDEC (2003/2008/2013/2018), Encuesta Permanente de Hogares. Bases de Datos de Gran Córdoba, Ondas tercer trimestre, 2003/2008/2013/2018, Buenos Aires, INDEC, https://www.indec.gob.ar/indec/web/InstitucionalIndec-BasesDeDatos .

Moscoloni, Nora (2011), Las nubes de datos. Métodos para analizar la complejidad, Rosario, UNR Editora.

Secretaría de Políticas Universitarias (2017), Sistema de Consulta de Estadísticas Universitarias, Buenos Aires, Ministerio de Educación, http:/ / estadisticasuniversitarias. me.gov.ar/ [Consulta: noviembre de 2020].

Stasiejko, Halina, Karina Edelmys Krauth, Jessica Loreley Pelayo Valente, Marta Alicia Mirko y Carla Eugenia Angellotti(2013), "Indagación de las concepciones acerca de la dilación en el estudio durante el ingreso a la universidad", Ponencia presentada en el V Congreso Internacional de Investigación y Práctica Profesional en Psicología XX Jornadas de Investigación Noveno Encuentro de Investigadores en Psicología del MERCOSUR, Buenos Aires, Facultad de Psicología-Universidad de Buenos Aires, noviembre.

Suasnábar, Claudio y Laura Inés Rovelli (2016) "Ampliaciones y desigualdades en el acceso y egreso de estudiantes a la Educación Superior en la Argentina", Pro-Posições, vol. 27, núm. 3, pp. 81-104.

Tinto, Vincent (1989), "Definir la deserción: una cuestión de perspectiva", Revista de Educación Superior, vol. 18, núm. 71, pp. s/d.

Tavela, Dania y Magalí Catino (2018) “Áreas de vacancia, vinculación, pertinencia y planificación del sistema universitario: una herramienta para abordar la expansión de la educación superior en territorio", Buenos Aires, Ministerio de Educación de la Nación, http:// www.bnm.me.gov.ar/giga l/documentos/EL006459. pdf [Consulta: mayo de 2019]. 
Anexo 1, Tabla 1. Campos de formación por universidad y tipo de titulación, Córdoba 2017

\begin{tabular}{|c|c|c|c|c|c|c|c|c|c|c|c|}
\hline$N^{\circ}$ & Campo de formación & Nivel & UNC & UTN & UPC & $\begin{array}{l}\text { IUA- } \\
\text { UD }\end{array}$ & ucc & UBP & UES 21 & IUCBC & Total U.U \\
\hline \multirow{2}{*}{1} & \multirow{2}{*}{$\begin{array}{l}\text { Administración y } \\
\text { comercio }\end{array}$} & Pregrado & 7 & 0 & 0 & 3 & 2 & 8 & 17 & 0 & 37 \\
\hline & & Grado & 2 & 0 & 0 & 4 & 3 & 11 & 16 & 0 & 36 \\
\hline \multirow{2}{*}{2} & \multirow{2}{*}{ Artes } & Pregrado & 0 & 0 & 8 & 0 & 0 & 0 & 0 & 0 & 8 \\
\hline & & Grado & 17 & 0 & 3 & 0 & 0 & 0 & 0 & 0 & 20 \\
\hline \multirow{2}{*}{3} & \multirow{2}{*}{$\begin{array}{l}\text { Conocimientos naturales, } \\
\text { físicos y matemáticos }\end{array}$} & Pregrado & 1 & 0 & 0 & 0 & 0 & 0 & 0 & 0 & 1 \\
\hline & & Grado & 10 & 0 & 0 & 0 & 1 & 0 & 0 & 0 & 11 \\
\hline \multirow{2}{*}{4} & \multirow{2}{*}{ Derecho y justicia } & Pregrado & 0 & 0 & 0 & 0 & 0 & 0 & 2 & 0 & 2 \\
\hline & & Grado & 3 & 0 & 0 & 0 & 2 & 4 & 3 & 0 & 12 \\
\hline \multirow{2}{*}{5} & \multirow{2}{*}{ Docencia y educación } & Pregrado & 0 & 0 & 0 & 0 & 0 & 0 & 0 & 0 & 0 \\
\hline & & Grado & 3 & 0 & 4 & 0 & 8 & 4 & 1 & 0 & 20 \\
\hline \multirow{2}{*}{6} & \multirow{2}{*}{ Educación Física } & Pregrado & 0 & 0 & 1 & 0 & 0 & 0 & 0 & 0 & 1 \\
\hline & & Grado & 0 & 0 & 1 & 0 & 0 & 1 & 0 & 0 & 2 \\
\hline \multirow{2}{*}{7} & \multirow{2}{*}{ Humanidades } & Pregrado & 1 & 0 & 0 & 0 & 0 & 0 & 0 & 0 & 1 \\
\hline & & Grado & 21 & 0 & 0 & 0 & 2 & 0 & 0 & 0 & 23 \\
\hline \multirow{2}{*}{8} & \multirow{2}{*}{$\begin{array}{l}\text { Preservación de } \\
\text { recursos naturales y } \\
\text { medioambiente }\end{array}$} & Pregrado & 0 & 0 & 1 & 0 & 0 & 0 & 1 & 0 & 2 \\
\hline & & Grado & 0 & 0 & 0 & 0 & 0 & 2 & 1 & 0 & 3 \\
\hline \multirow{2}{*}{9} & \multirow{2}{*}{$\begin{array}{l}\text { Procesos productivos, } \\
\text { diseño y construcciones }\end{array}$} & Pregrado & 1 & 5 & 0 & 0 & 0 & 0 & 1 & 0 & 7 \\
\hline & & Grado & 13 & 8 & 1 & 2 & 6 & 3 & 3 & 0 & 36 \\
\hline \multirow{2}{*}{10} & \multirow{2}{*}{$\begin{array}{l}\text { Procesos sociales, } \\
\text { culturales y políticos }\end{array}$} & Pregrado & 0 & 1 & 0 & 0 & 0 & 0 & 0 & 0 & 1 \\
\hline & & Grado & 10 & 0 & 0 & 0 & 6 & 2 & 6 & 0 & 24 \\
\hline \multirow{2}{*}{11} & \multirow{2}{*}{$\begin{array}{l}\text { Producción agropecuaria } \\
\text { y alimentaria, y salud } \\
\text { animal }\end{array}$} & Pregrado & 2 & 1 & 0 & 0 & 1 & 0 & 0 & 0 & 4 \\
\hline & & Grado & 1 & 0 & 0 & 0 & 3 & 0 & 0 & 0 & 4 \\
\hline \multirow{2}{*}{12} & \multirow{2}{*}{ Salud humana } & Pregrado & 4 & 0 & 0 & 0 & 3 & 0 & 0 & 0 & 7 \\
\hline & & Grado & 15 & 0 & 1 & 0 & 10 & 0 & 1 & 1 & 28 \\
\hline \multirow{2}{*}{13} & \multirow{2}{*}{$\begin{array}{l}\text { Servicios turísticos, } \\
\text { hoteleros y gastronómicos }\end{array}$} & Pregrado & 1 & 0 & 0 & 0 & 0 & 1 & 1 & 0 & 3 \\
\hline & & Grado & 0 & 0 & 1 & 0 & 0 & 3 & 4 & 0 & 8 \\
\hline \multirow{2}{*}{14} & \multirow{2}{*}{$\begin{array}{l}\text { Tecnología de la } \\
\text { información y la } \\
\text { comunicación }\end{array}$} & Pregrado & 8 & 2 & 0 & 2 & 0 & 0 & 1 & 0 & 13 \\
\hline & & Grado & 4 & 2 & 0 & 3 & 1 & 9 & 5 & 0 & 24 \\
\hline & Total de titulaciones & & 124 & 19 & 21 & 14 & 48 & 48 & 63 & 1 & 338 \\
\hline
\end{tabular}

Fuente: elaboración propia en base a datos de la SPU. 


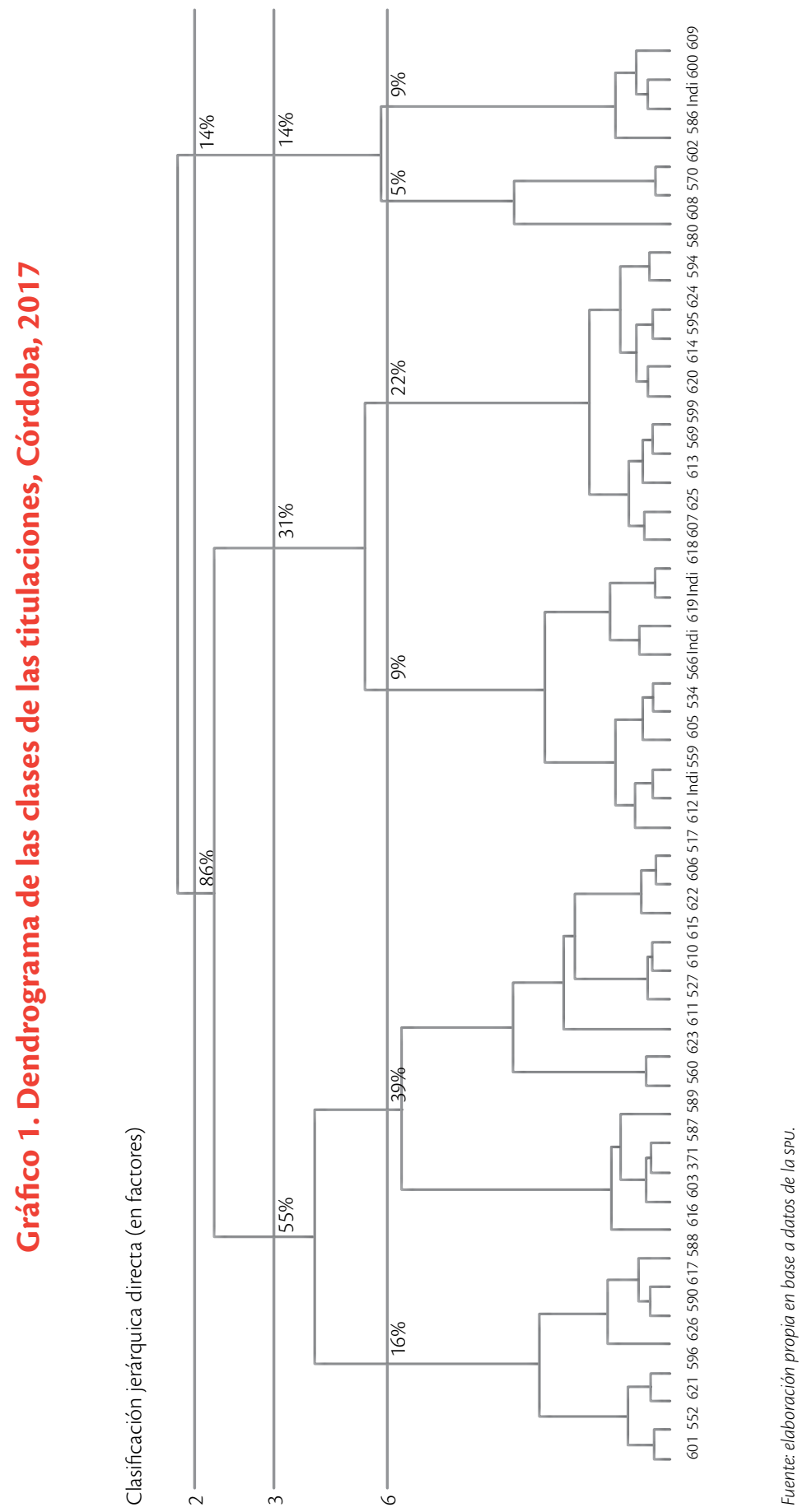

\section{Cómo citar este artículo:}

Antolin-Solache, Ana-María y Manuel-Alejandro Giovine, (2021), "Estrategias de permanencia e instrumentos de reproducción universitarios en Córdoba, Argentina, 2017", Revista Iberoamericana de Educación Superior (RIES), vol. XII, núm. 35, pp. 70-90, DOI: https:// doi.org/10.22201/iisue.20072872e.2021.35.1083 [Consulta: fecha de última consulta]. 